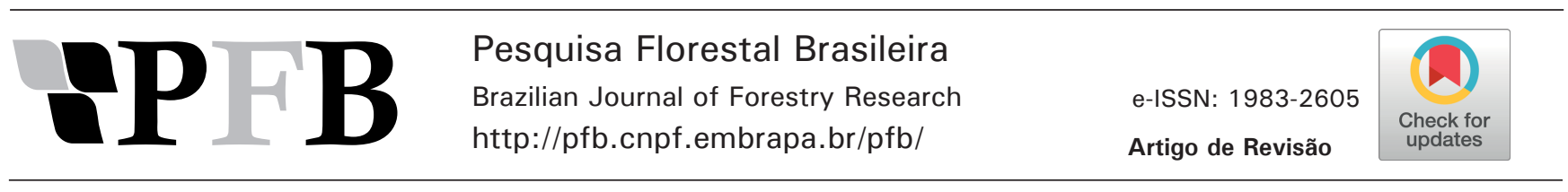

\title{
Anatomia de hastes adultas de bambu: uma revisão
}

\author{
Fernando Rusch ${ }^{1 *(\mathbb{D})}$, Éverton Hillig'(i), Guilherme Bordignon Ceolin' ${ }^{1}$ \\ ${ }^{1}$ Universidade Estadual do Centro-Oeste, Departamento de Engenharia Florestal, BR 153, Km 07, CEP 84500-000, Irati, PR, Brasil \\ ${ }^{2}$ Universidade Federal de Santa Maria, Departamento de Engenharia Florestal, Rua 7 de Setembro, BR 386, Km 40, CEP 98400-000, Frederico Westphalen, RS, Brasil
}

*Autor correspondente:

fe_rusch@yahoo.com.br

Termos para indexação:

Monocotiledôneas

Feixes fibrovasculares

Lignocelulose

Index terms:

Monocotyledons

Fibrovascular bundles

Lignocellulosic

Histórico do artigo:

Received in 04/11/2017

Accepted in 20/08/2018

Published in 19/10/2018

doi: 10.4336/2018.pfb.38e201701530

\section{Introdução}

Bambus (Poaceae, Bambusoideae) são monocotiledôneas perenes, de rápido crescimento. Seu corpo vegetativo é constituído por materiais ligno-celulósicos formados por feixes líbero-lenhosos e envolvidos por células de parênquima, isto é, um tecido aproximadamente circular, englobando feixes vasculares de floema primário (líber) e tecido vascular de xilema primário (Panda, 2011;

\begin{abstract}
Resumo - Bambus são monocotiledôneas de rápido crescimento, consideradas como regeneradoras ambientais devido à sua capacidade de ocupar solos degradados, reduzindo o processo erosivo. Além disso, várias de suas espécies são utilizadas como matérias primas ligno-celulósicas para diversos usos. Devido à grande importância deste grupo, esse trabalho teve como objetivo estudar a anatomia de hastes adultas de diferentes espécies de bambu, a fim de melhor caracterizar as diferenças estruturais existentes entre grupos. Foram levantadas em literatura informações sobre a caracterização morfológica e anatomia, com destaque para os padrões de classificação de fibras, células de parênquima, bainha de esclerênquima e canais condutores/vasculares (xilema e floema) de diferentes espécies de bambu. As diferenças anatômicas possibilitaram classificar o material em quatro diferentes grupos, sendo os aspectos mais relevantes a forma do feixe fibrovascular e o teor de fibra.
\end{abstract}

\section{Stem anatomy of adult bamboo species: a review}

\begin{abstract}
Bamboos are fast-growing monocotyledonous considered as environmental regenerators due to their ability to occupy degraded soils, decreasing erosive processes. Bamboos are also largely used as ligno-cellulosic raw material for several purposes. Due to their outstanding importance, the objective of this paper was to study the stem anatomy of different adult bamboo species to better characterize the structural divergences among different groups. Information was collected from literature review on morphological and anatomical characteristics, as fiber classification, parenchymatous cells, sclerenchyma sheaths and vascular bundles (xylem/phloem) of several bamboo species. Bamboo species may be sorted in four groups, considering mainly differences of vascular bundle shape and percentage of fibers.
\end{abstract}

Yeasmin et al., 2014). O porte das diferentes espécies de bambu varia desde herbáceos não lignificados, com poucos $\mathrm{cm}$ de altura, até bambus lenhosos de médio e grande porte, podendo atingir mais de $30 \mathrm{~m}$ de altura e $20 \mathrm{~cm}$ de diâmetro (Miranda et al., 2017).

Os registros científicos atuais, baseados largamente em análises filogenéticas (Bamboo Phylogeny Group, 2012), informam que existem no mundo 119 gêneros com 
1.482 espécies de bambu, classificados em três tribos: (1) Arundinarieae (546 espécies), que são bambus lenhosos de climas temperados, apesar de alguns ocorrerem em altas elevações nos trópicos; (2) Bambuseae (812 espécies), que são bambus lenhosos de climas tropicais, mesmo que alguns ocorram fora dos trópicos e (3) Olyreae (124 espécies), que são bambus herbáceos (Clark et al., 2015; Nayak \& Mishra, 2016), esses de menor porte, que ocorrem no sub-bosque de florestas, apresentando colmos não lignificados e intolerância à radiação solar direta (Greco \& Zannin, 2017). Ainda que seja um grupo bem estudado, esses números continuam aumentando, devido às novas descobertas de espécies e gêneros (Bamboo Phylogeny Group, 2012).

As plantas de bambu são encontradas em quase todos os continentes, distribuindo-se em regiões tropicais, subtropicais e temperadas da Ásia, América, África e Oceania, numa faixa latitudinal de $51^{\circ} \mathrm{N}$ no Japão à $47^{\circ} \mathrm{S}$ na Argentina, desde o nível do mar até $4.000 \mathrm{~m}$ de altitude, embora a ocorrência de bambus herbáceos nunca exceda uma altitude de $1.500 \mathrm{~m}$. Na América Latina ocorrem mais de 400 espécies, riqueza esta inferior às estimativas asiáticas, mas superiores às da África. No Brasil, são descritas até o momento 258 espécies nativas, sendo que, destas, 175 espécies em 12 gêneros são consideradas endêmicas (Filgueiras \& Viana, 2017). Não obstante a maior diversidade desta planta ser encontrada no Sudeste Asiático e na América do Sul (Panda, 2011; Hakeem et al., 2015), muitas espécies são factíveis de serem introduzidas em outros locais, justamente por ocuparem uma ampla variedade de nichos ecológicos.

O termo "bambu" teve sua origem, provavelmente, no barulho provocado pelo estouro de seu colmo quando submetido ao fogo, ou seja, "bam-boo" (Greco \& Cromberg, 2011). Esse material é utilizado desde os tempos mais remotos (Banik, 2015) para inúmeros fins, podendo-se citar alimentação, tanto para os seres humanos como para animais, construção civil, movelaria, artesanato, fabricação de produtos têxteis, biomassa energética e outras matérias-primas industriais para os mais diferentes produtos (Smole, 2013). Deste modo, os bambus, por serem um recurso disponível em abundância em diversas regiões do mundo como fontes de matéria-prima, desempenham um importante papel no processo de desenvolvimento socioeconômico de algumas regiões (Yeasmin et al., 2014). Além disso, é o grupo de plantas com a mais alta taxa de crescimento em biomassa no mundo (Chaowana et al., 2014; Okahisa et al., 2018).
Como exemplo, podem-se citar algumas espécies do gênero Bambusa, cujo incremento da biomassa pode variar de 50 a 100 t ha ano ${ }^{-1}$, dependendo das condições do local (Dias Junior et al., 2014). Todavia, apesar de todos estes atributos, não mais do que 50 espécies são utilizadas comercialmente até o momento. Portanto, é de suma importância investigar o emprego desta matéria-prima não convencional em diferentes produtos e setores (Nayak \& Mishra, 2016).

Em termos morfo-anatômicos, os tecidos que formam o bambu apresentam somente crescimento primário e são constituídos por uma mistura de lignina, hemicelulose e celulose, organizadas em feixes fibrovasculares e células parenquimatosas (Liese, 1980, 1985, 1998; Nayak \& Mishra, 2016). Suas características marcantes são o formato alongado, grandes dimensões, estabilidade dimensional e alta resistência mecânica. Todavia, a espessura da parede celular das fibras varia ao longo da altura da haste e, em função disso, suas propriedades físicas e mecânicas também variam desde um extremo até o outro do bambu, o que pode causar dificuldades adicionais para a utilização desse material. Desta forma, esse trabalho teve como objetivo compilar informações da literatura sobre a anatomia de hastes de diferentes gêneros e espécies de bambu, visando sua caracterização anatômica.

\section{Características morfológicas dos colmos de bambu}

Diferentemente da maioria das plantas lignocelulósicas, o bambu adulto não apresenta um tronco, mas um conjunto de colmos empilhados, que formam uma haste. Seus principais componentes estruturais são as raízes, rizomas, colmos, ramos, folhas e flores. O número de colmos encontrados em uma única haste de bambu varia conforme a espécie. O florescimento e a frutificação ocorrem somente entre 30 e 130 anos (Banik, 2015). Portanto, as estruturas mais estudadas em bambus são colmos e rizomas.

O colmo é a parte superior ao solo mais distinguível da planta, sendo caracterizado como um tubo cilíndrico e oco, com formato arqueado, semiarqueado ou ereto (Chaowana, 2013; Liese \& Tang, 2015), compreendendo dois nós, sendo que o comprimento do entrenó difere consideravelmente entre as espécies. Geralmente, o comprimento dos entrenós é maior no meio da haste e, comparativamente, nas espécies em que o período de crescimento começa mais cedo. Uma característica importante é a espessura de suas paredes, pois apresentam grande impacto nas propriedades mecânicas (Banik, 2015; Nayak \& Mishra, 2016). 
Na parede do colmo, o número de feixes vasculares sofre pouca variação com o aumento da altura da haste de bambu, enquanto a fração de parênquima do tecido diminui (Banik, 2015; Liese \& Tang, 2015; Nayak \& Mishra, 2016). Assim, da base para o topo, a redução no diâmetro de um colmo é bastante particular de cada espécie. Isto vem acompanhado também por uma redução da espessura de parede do colmo, devido à menor proporção de células de parênquima, resultando em aumento da sua densidade nas regiões mais apicais (Liese \& Tang, 2015; Okahisa et al., 2018). Ainda que a estrutura anatômica de um colmo de bambu seja geralmente bastante uniforme, apresentando pequenas variações entre espécies, algumas espécies são mais adequadas para usos distintos.

O colmo é complementado pelo sistema de ramificação aérea, composto por ramos e folhas. Existem dois tipos de folhagem: uma denominada bainha de colmo, ou folha caulinar, e a outra chamada de folhas verdes. A bainha é uma folha modificada, provisória, grande e rígida, com as mesmas partes das folhas tradicionais, mas em proporções diferentes. Apresenta-se como uma estrutura de revestimento que ocorre na fase inicial de crescimento, caindo à medida que o bambu se transforma em um indivíduo maduro. Esta folhagem protege o rebento de bambu (broto) durante a fase inicial de seu crescimento, até atingir o tamanho adulto (Janssen, 2000). As folhas verdes ocorrem, por sua vez, nos indivíduos adultos que já perderam as folhas caulinares (Banik, 2015; Nayak \& Mishra, 2016). Em torno do quinto nó do colmo, ou entre 150 e $200 \mathrm{~cm}$ acima do nível do solo, está o ponto em que a bainha do colmo possui todas as características típicas da espécie. No local de fixação existem diferentes combinações de características envolvendo a aurícula, as cerdas e as lígulas. Essas características, assim como suas cores, são traços importantes para a identificação das espécies. As aurículas e cerdas podem ou não estar presentes. Caso ocorram, estas estruturas se localizarão em cada lado das bordas, tanto em bainhas do caule como na folhagem verde dos bambus adultos. A lígula está localizada internamente, entre as aurículas e cerdas localizadas de cada lado na bainha (Banik, 2015).

Os rizomas são os caules subterrâneos de um bambu, os quais servem para captação, transporte e armazenamento de nutrientes e para reprodução vegetativa através do desenvolvimento lateral, podendo se converter em brotos ou em um novo rizoma. Além disso, quando bem desenvolvidos, são bastante ramificados e possuem função estrutural. A composição de seus tecidos compreende, em média, $62 \%$ de células de parênquima, $20 \%$ de fibras e $18 \%$ de tecidos condutores, formados pelo xilema e floema (Nayak \& Mishra, 2016). Os rizomas, do ponto de vista anatômico, são diferentes dos colmos, mas semelhantes na sua subdivisão, por apresentarem nós e entrenós, ainda que estes últimos sejam mais curtos e possuam menor diâmetro (Nayak \& Mishra, 2016). A importância dos rizomas reside no fato de que tanto o crescimento quanto a ramificação padrão dos bambus dependem dos dois principais sistemas de rizomas, denominados de paquimorfos (simpodial ou entouceirante) ou leptomorfos (monopodial ou alastrante). As espécies com rizomas leptomorfos, muitas vezes, apresentam tilos nos feixes fibro-vasculares no espaço intercelular entre os dois vasos de metaxilema. Naquelas com sistema de rizoma paquimorfo, isto não ocorre. Devido a estas diferenças, a presença de tilos pode ser utilizada como uma característica diagnóstica (Grosser \& Liese, 1971).

\section{Características anatômicas dos colmos de bambu}

A estrutura dos colmos de um bambu compõe-se externamente de uma epiderme e internamente por outros dois tecidos, formado por células de parênquima e feixes fibrovasculares (Habibi \& Lu, 2014). Estes últimos são constituídos por células lignificadas e espessas, formada por numerosos feixes de fibras e células esclerenquimáticas, o que dificulta a movimentação lateral de líquidos nos colmos (Pereira \& Beraldo, 2007). Na parte externa, os colmos são revestidos por uma camada de cera e por outra de cutina, que é rica em sílica (Figura 1), conferindo resistência e proteção contra o ataque de animais. Essa característica também provoca o desgaste de ferramentas de corte (Janssen, 2000).

Via de regra, anatomicamente, os colmos são formados por células de parênquima (50\%), feixes de fibras $(40 \%)$ e feixes vasculares (10\%) (Liese, 1980, 1998; Pereira \& Beraldo, 2007; Liese \& Tang, 2015; Nayak $\&$ Mishra, 2016). Na maioria das espécies, as $10 \%$ das fibras concentram-se na área interna do colmo e $60 \%$ na região próxima à casca (Janssen, 2000). Por sua vez, o percentual de parênquima cresce da região mais próxima à casca para o interior da parede do bambu, com o inverso ocorrendo com os feixes fibrovasculares, os quais são mais numerosos em camadas mais próximas da casca. 

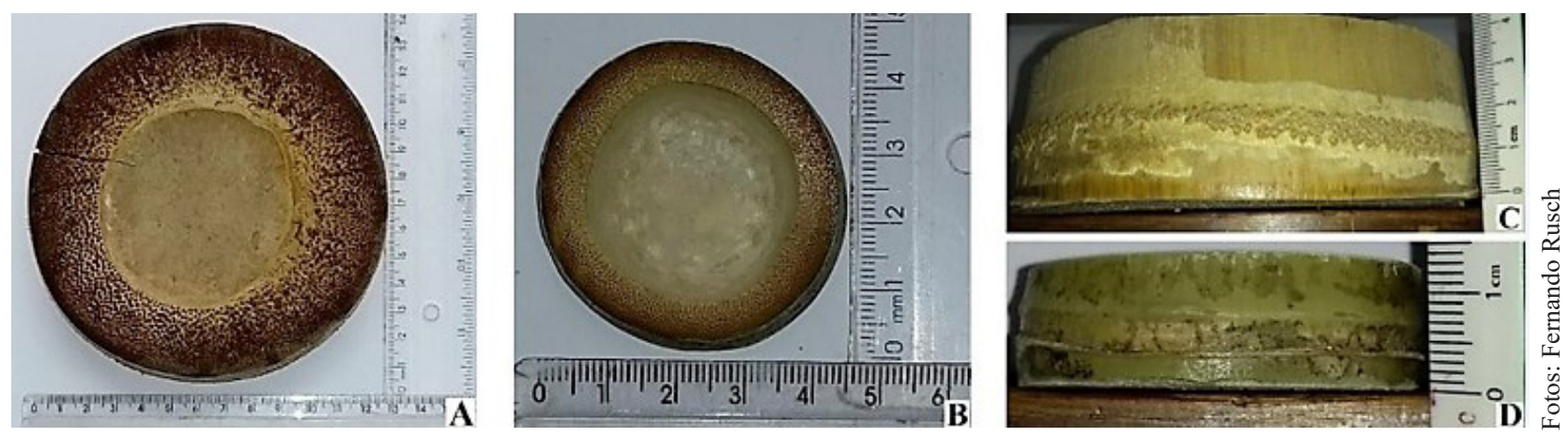

Figura 1. Representação transversal e axial do colmo de duas espécies de bambu. Seção transversal na região do nó: A) Dendrocalamus asper e B) Phyllostachys aurea. Seção axial na região do nó: C) Dendrocalamus asper e D) Phyllostachys aurea.

Figure 1. Transverse and axial representation of the stem the of two bamboo species. Cross section in the node region:

A) Dendrocalamus asper and B) Phyllostachys aurea. Axial section in the node region: C) Dendrocalamus asper and

D) Phyllostachys aurea.

Comparativamente à estrutura da madeira, a estrutura anatômica dos colmos é constituída por fibras com maiores dimensões de parede celular incorporadas em lignina (Ghavami et al., 2003), apresentando uma variação na organização da seção transversal no nó do colmo. Nessa região, ocorrem numerosos feixes fibrovasculares envolvidos por células de parênquima (Tomazello Filho \& Azzini, 1988), as quais são ricas em substâncias de reserva na forma de amidos (Liese, 1980, 1985). Nos entrenós, os feixes vasculares são constituídos por elementos de vaso de metaxilema, floema, bainha de fibras de protoxilema e, dependendo da espécie, de feixes de fibras adicionais (Liese, 1998).
A maior concentração dos feixes de fibras ocorre na região próxima da casca, de coloração mais escura, conferindo maior resistência. Em contraste, na face oposta, próximo ao centro do colmo, ocorre maior concentração de células de parênquima, de coloração mais clara, proporcionando menor resistência (Janssen, 2000). Os feixes fibrovasculares, com seus aglomerados de fibras dentro do tecido do parênquima, contribuem fortemente para o caráter estrutural (Liese \& Tang, 2015). Na Figura 2, são apresentados os feixes fibrovasculares, no sentido transversal das espécies Dendrocalamus asper e Phyllostachys aurea.
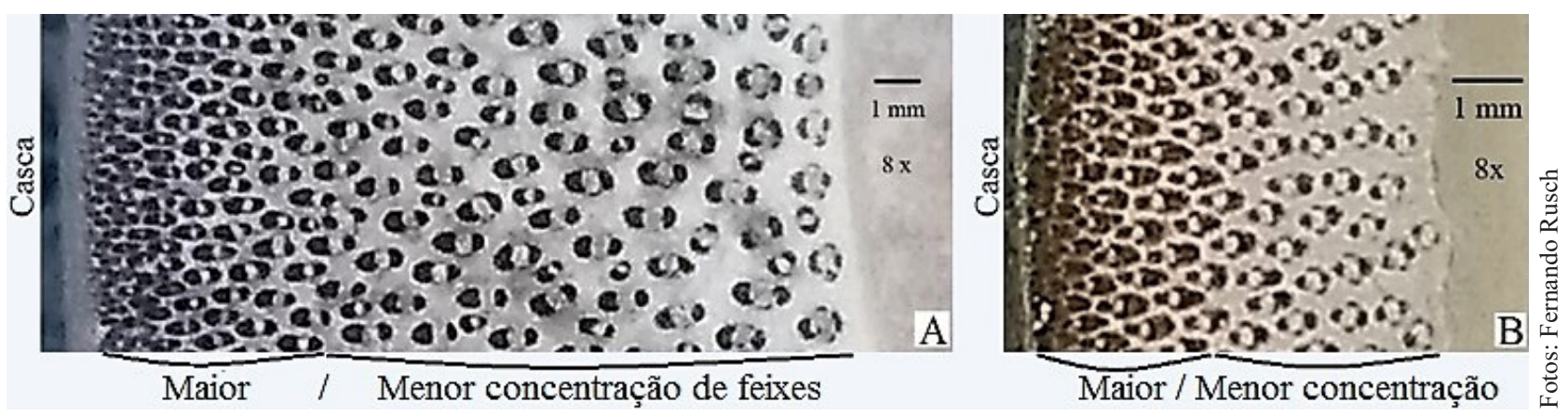

Figura 2. Representação de lâminas com os feixes fibrovasculares. A) Dendrocalamus asper e B) Phyllostachys aurea.

Figure 2. Laminae representation with the fibrovascular bundles. A) Dendrocalamus asper and B) Phyllostachys aurea.

$\mathrm{Na}$ estrutura anatômica dos entrenós de bambu, as células estão dispostas no sentido longitudinal, não apresentando células dispostas no sentido radial (Liese, 1980). Na seção transversal do nó ocorrem numerosos feixes fibrovasculares envolvidos por células de parênquima, com uma epiderme constituída por células epiteliais e de esclerênquima. 
Os feixes fibrovasculares da região nodal seguem de forma direta e indireta de um entrenó para o outro. Nessa região, parte destes feixes se bifurca, conectando-se com: (i) a zona periférica ou parte externa da epiderme, constituída pelo anel nodular ou anel da bainha ou com a gema dormente; ou então, com (ii) a zona interna ou vasos do diafragma do nó, conforme ilustrado na Figura 3.
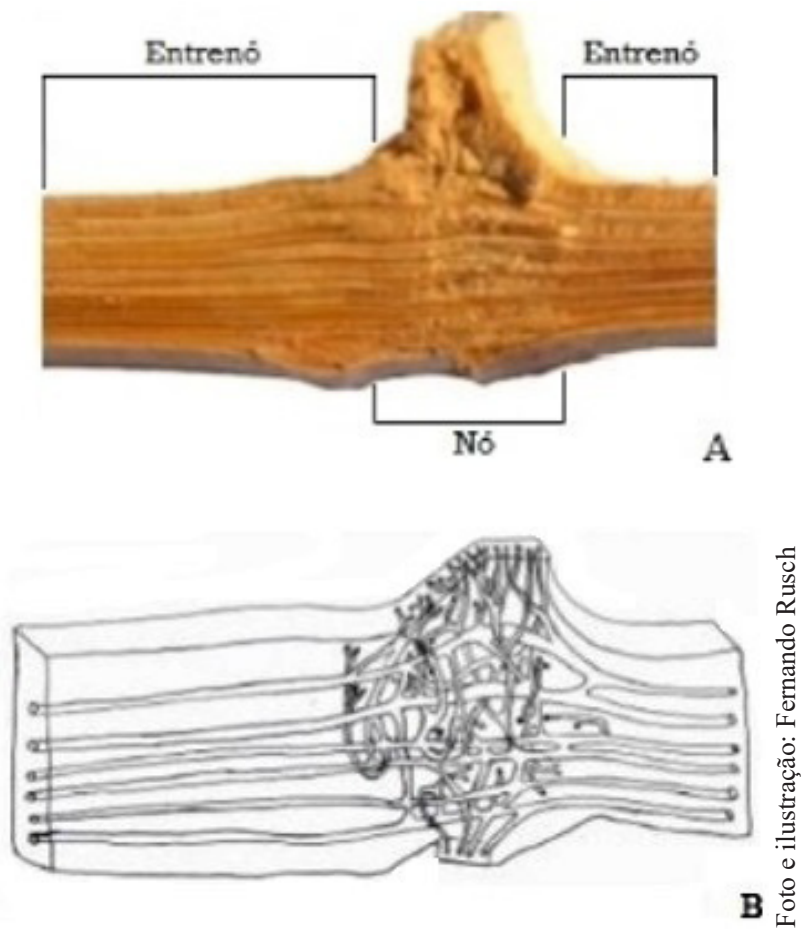

Figura 3. Feixes fibrovasculares da região do nó e do entrenó. A) Representação da região do nó e entrenó em bambu; B) Ilustração da estrutura interna desses feixes no interior do colmo.

Figure 3. Fibrovascular bundles of the node and internade region. A) Representation of the node and internade region in bamboo; B) Internal structure illustration of these bundles inside the stem.

Dessa forma, dentro do nó ocorrem várias ramificações dos vasos, que possibilitam sua conexão tanto ao entrenó superior quanto ao inferior (Liese, 1980, 1985). Além disso, ocorrem bifurcações secundárias de menor espessura, que são responsáveis pela conexão com os diafragmas nodais, ligando a parte periférica e a parte interna do nó (Pereira, 2012).

Com relação à estrutura das fibras, Parameswaran \& Liese (1976) constataram que seu comprimento varia de $2 \mathrm{~mm}$ até $4 \mathrm{~mm}$, entre e dentro das espécies. Nas células de parênquima podem ocorrer dois padrões de comprimento.
A parede celular das células mais curtas, com citoplasma mais denso, permanece na maior parte não-lignificada, mesmo em colmos maduros. As células mais longas apresentam uma estrutura poli-laminada, constituída por diversas lamelas com orientação de fibrilas alternadas, de forma análoga ao que ocorre na parede celular das fibras, as quais tornam-se lignificadas, gradualmente, com o envelhecimento do indivíduo (Parameswaran \& Liese, 1976; Nayak \& Mishra, 2016).

Os feixes vasculares incorporados no tecido parenquimático influenciam a flexibilidade e a estabilidade do colmo (Nayak \& Mishra, 2016). No bambu ocorrem dois tipos de orientação de microfibrilas: as lamelas estreitas se alinham com ângulo fibrilar de $80^{\circ}$ a $90^{\circ}$ em relação ao eixo vertical, e as mais amplas alinham-se com ângulo fibrilar de $2^{\circ}$ até $20^{\circ}$, podendo ser consideradas quase que paralelas ao eixo longitudinal (Wang et al., 2012). Entretanto, nas espécies arbóreas a orientação da maioria das microfibrilas da camada S2 da parede celular está alinhada quase que paralelamente ao eixo axial.

O parênquima é o tecido que aparece em maior proporção, sendo o local onde os feixes fibrovasculares são incorporados, fazendo com que ambos os elementos contribuam conjuntamente para sua estabilidade e flexibilidade (Liese \& Tang, 2015). O parênquima possui como principal função estocar nutrientes e água, podendo armazenar quantidades significativas de amido (Beraldo \& Azzini, 2004). Comumente, as células do parênquima são menores na parte externa do bambu e crescem gradativamente em direção à sua parte interna. Nas camadas da parede interna do bambu, o parênquima encontra-se concentrado, representando de $40 \%$ a $60 \%$ de sua composição. Todavia, nas camadas externas o mesmo diminui gradativamente. Na direção longitudinal, ocorre redução da concentração de parênquima no sentido base-topo, com média de $60 \%$ na base e de $40 \%$ na parte apical (Liese \& Tang, 2015).

Os feixes vasculares constituem, aproximadamente, $10 \%$ da proporção do colmo, representando seus principais espaços vazios, sendo o ponto de menor resistência mecânica. Estes feixes, os quais compreendem o xilema e o floema primários, são menores e mais numerosos na periferia do colmo e maiores e em menor número na sua parte interna (Beraldo \& Azzini, 2004). No interior da parede do colmo, o número total de feixes diminui da base para o topo, porém sua densidade aumenta (Pereira \& Beraldo, 2007). 


\section{Padrões para classificação de bambu}

Nas décadas de 1960 e 1970, Grosser \& Liese (1971) examinaram atentamente o parênquima e os feixes vasculares em diversas espécies de bambu. Nessa pesquisa, foi realizada a caracterização da estrutura anatômica de hastes adultas de diferentes gêneros e espécies de bambu por meio de amostras de colmos coletadas em vários países asiáticos, mais especificamente nos seguintes locais: Índia (DehraDun, F.R., Jardim Botânico), Bangladesh (Florestas em torno de Chittagong/Bengal Oriental, na obra referidos como Paquistão), Tailândia (província de Kanchanaburi), Indonésia (Bogor, Jardim Botânico), Filipinas (Laguna, Campus Florestal), Taiwan (Floresta experimental da Universidade Nacional de Taiwan) e Japão (Floresta de Kyoto). Além desses, alguns colmos completos de várias espécies, recolhidos entre 1957 e 1960, em DehraDun e Bogor, foram utilizados para investigações adicionais. Desta forma, foram avaliados 1.200 entrenós de 250 colmos de 52 espécies pertencentes a 14 gêneros, permitindo caracterizar diversos aspectos anatômicos, além de classificar as espécies em virtude de seus feixes vasculares.

A partir do trabalho de Grosser \& Liese (1971), tornou-se possível classificar, de maneira genérica, o feixe vascular no colmo de bambu como sendo constituído por dois vasos de metaxilema maiores (40$120 \mu \mathrm{m}$ ) com um ou dois elementos de protoxilema, com o floema em forma de tubos crivados de parede fina, nãoligados e conectados com células companheiras. Esse tecido condutor funciona ao longo da vida do bambu sem adição de qualquer novo tecido condutor, em contraste às madeiras de coníferas e dicotiledôneas, que possuem atividade cambial. Em bambus mais antigos, os vasos e os tubos crivados às vezes tornam-se impermeáveis, devido ao depósito de substâncias semelhantes à goma. Também ocorre o bloqueio de tubos crivados, por expansões semelhantes à tilose (Liese, 1980). A Figura 4 ilustra as estruturas de um feixe fibrovascular.

Para Fujii (1985), a maior concentração de feixes vasculares foi verificada na parte externa superior da haste de bambu ( 3 feixes $\mathrm{mm}^{-2}$ ), sendo mais baixa $(0,5$ feixes $\mathrm{mm}^{-2}$ ) na parte interna da base. Com relação à distribuição dos feixes vasculares, o mesmo autor constatou que 50$80 \%$ estão localizados no terço externo da parede, $10-35 \%$ no meio e apenas $10-20 \%$ no terço interno. Assim, para determinar o número e densidade, o tamanho médio é um fator importante, sendo que quanto maiores os feixes, menor o número presente numa dada área. O floema, os vasos do metaxilema e os espaços intercelulares derivados dos elementos do protoxilema de um feixe vascular são circundados por: (i) bainhas de fibras; (ii) cordão de esclerênquima; e (iii) células de parênquima, diferindo em tamanho e forma, de acordo com as espécies de bambu e sua posição dentro do colmo.

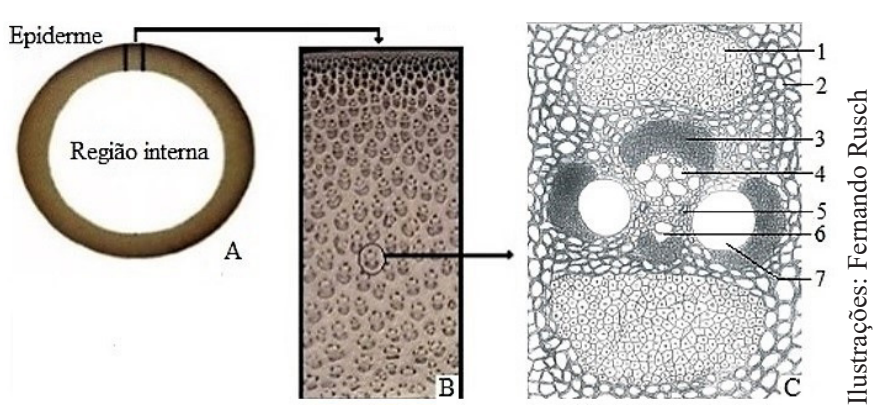

Figura 4. Representação de feixes fibrovasculares. A) Seção transversal do colmo; B) Faixa da seção transversal; C) estrutura de um feixe fibrovascular embutido em tecido de parênquima, com descrição de seus elementos: (1) bainha de fibras; (2) células de parênquima; (3) bainha esclerênquima; (4) floema; (5) pequenos elementos do metaxilema; (6) espaço intercelular derivado do protoxilema; (7) vasos de metaxilema

Figure 4. Representation of fibrovascular bundles. A) Cross section of the stem; B) transversal section; C) structure of a fibrovascular bundle embedded in parenchyma tissue, with description of its elements: (1) fiber sheath; (2) parenchyma cells; (3) sclerenchyma sheath; (4) phloem; (5) small metaxylem elements; (6) intercellular space derived from the protoxilem; (7) metaxylem vessels.

Devido a essas diferenças anatômicas dos feixes vasculares (forma, quantidade e tamanho), que também são influenciadas pela altura do entrenó e sua espessura de parede, é possível estabelecer uma classificação de diferentes tipos de bambu. Atualmente, é possível agrupar os gêneros de bambu em quatro tipos (Tabela 1): o tipo I engloba todos os leptomorfos (espécies alastrantes), que exibem semelhança na estrutura dos seus feixes vasculares. Os tipos anatômicos II, III e IV são representados pelos paquimorfos (espécies entouceirantes) (Grosser\& Liese, 1971; Liese, 1980, 1985).

Apesar de existir um padrão de tecido semelhante em cada entrenó, com forma, tamanho e distribuição dos feixes fibrovasculares definidos para cada seção, ocorre variação dessas características entre os entrenós, que também são influenciados pela posição em altura na haste, tornando-se menores no sentido base-topo. 
Da mesma forma, essas são influenciadas pela redução gradual da espessura da parede. Isto significa que existe uma estreita correlação entre as características morfológicas e histológicas, sendo que quanto mais se reduz a espessura da parede, maiores são as diferenças anatômicas (Liese, 1980, 1985).

Assim, devido a esta variação na forma, tamanho e padrão dos feixes vasculares, um entrenó da base do colmo pode exibir uma estrutura diferente da parte do meio, a qual, por sua vez, pode igualmente diferir da parte superior do colmo. Esta afirmação se confirma quando se verifica que em todas as espécies de bambu investigadas, o tamanho dos feixes vasculares diminui de forma constante da base para o topo. Esta tendência é mais acentuada em espécies que possuem feixes grandes na base (Grosser \& Liese, 1971).

Tabela 1. Classificação dos tipos de feixes vasculares básicos em bambus.

Table 1. Classification of basic vascular bundle types in bamboos.

\begin{tabular}{|c|c|c|}
\hline Tipo & Características & Ocorrência* \\
\hline I & $\begin{array}{l}\text { Formado de uma única parte, ou seja, da cadeia vascular } \\
\text { central, apresentando apenas as bainhas de esclerênquima } \\
\text { como tecido de suporte. Além disso, no seu espaço } \\
\text { intercelular ocorrem tiloses. }\end{array}$ & $\begin{array}{l}\text { Nesse tipo estão agrupadas as espécies com rizomas leptomorfos (gêneros alastrantes), } \\
\text { bastante invasivos, que se desenvolvem a partir da formação de uma complexa } \\
\text { rede de rizomas subterrâneos, formada pelos gêneros Arundinaria, Phyllostachys e } \\
\text { Tetragonocalamus. }\end{array}$ \\
\hline II & $\begin{array}{l}\text { Semelhante ao anterior (com uma cadeia vascular central), } \\
\text { contudo o espaço intercelular é maior, além de não ocorrer } \\
\text { tilose. }\end{array}$ & $\begin{array}{l}\text { Formado por bambus que apresentam rizomas paquimorfos (entouceirantes) ou } \\
\text { piramidais, em aglomerado ou em formação única, subdivididos em dois grupos: um } \\
\text { formado pelos gêneros Melocanna, Schizostachyum e Teinostachyum, em que ocorrem } \\
\text { feixes vasculares do tipo II e III nos entrenós basais; e outro formado pelo gênero } \\
\text { Cephalostachyum, onde ocorrem somente feixes vasculares do tipo II. }\end{array}$ \\
\hline III & $\begin{array}{l}\text { Apresenta duas partes, sendo uma cadeia vascular central } \\
\text { (com fio de fibra) e uma de fibras (afastada e abaixo da } \\
\text { cadeia vascular), mas com espaço intercelular menor que } \\
\text { os tipos anteriores. }\end{array}$ & $\begin{array}{l}\text { Nas espécies que possuem rizomas paquimorfos (entouceirantes) amontoados, sendo } \\
\text { alguns do gênero Oxytenanthera, com apenas este tipo, contudo os colmos basais, de } \\
\text { Bambusa, Dendrocalamus, Gigantochloa e Thyrsostachys podem estar combinados } \\
\text { com o tipo IV, enquanto Melocanna, Schizostachyum e Teinostachyum, combinados } \\
\text { com o tipo II. }\end{array}$ \\
\hline IV & $\begin{array}{l}\text { Apresenta três partes, sendo uma cadeia vascular central } \\
\text { (com fio de fibra) e outras duas de feixes de fibras em } \\
\text { lados opostos. }\end{array}$ & $\begin{array}{l}\text { Em espécies formadoras de aglomerados com rizomas paquimorfos (entouceirantes), } \\
\text { como os gêneros Bambusa, Dendrocalamus, Gigantochloa e Thyrsostachys, ocorrem } \\
\text { sempre combinados com o tipo III, principalmente nos colmos basais, porém raramente } \\
\text { nos medianos. }\end{array}$ \\
\hline
\end{tabular}

Fonte: Modificado de Grosser \& Liese (1971) e Liese (1980, 1985).

Em virtude do exposto, os autores deste trabalho propõem um sistema de classificação anatômica dos feixes vasculares, conforme ilustrados na Figura 5.

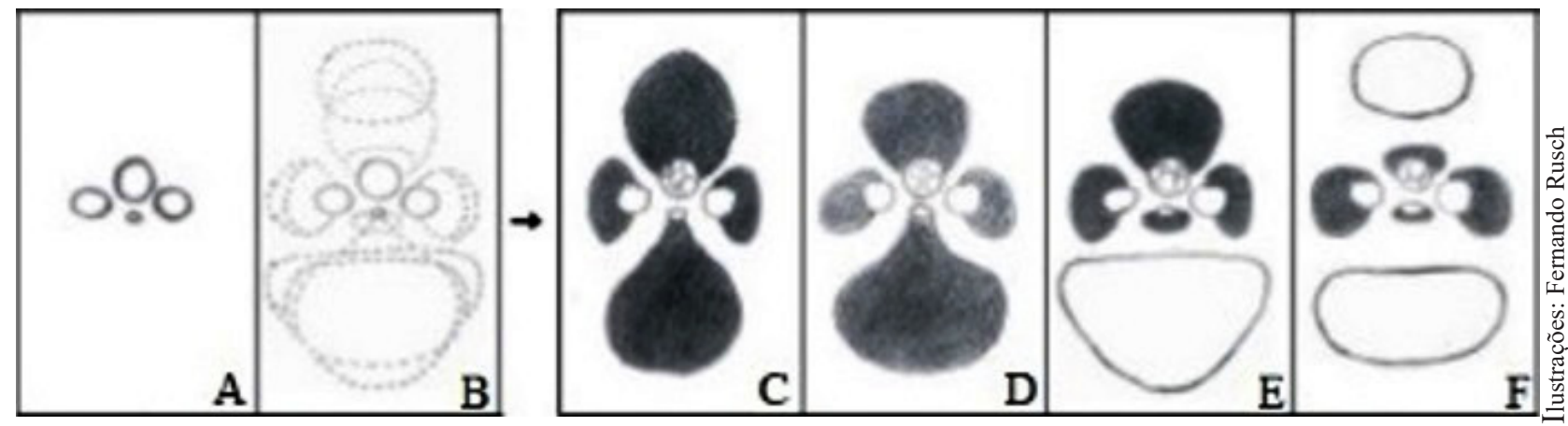

Figura 5. Ilustrações do formato padrão e dos diferentes tipos de feixes fibrovasculares. A) elementos básicos de um feixe vascular padrão em todas as espécies; B) variações que ocorrem nos diferentes tipos; C) tipo I; D) tipo II; E) tipo III; F) tipo IV.

Figure 5. Illustrations of the standard format and the different types of fibrovascular bundles. A) basic elements a standard vascular bundle in all species; B) variations that occur in the different types; C) type I; D) type II; E) type III; F) type IV. 
Os tecidos condutores, sendo tanto os vasos de metaxilema quanto do floema, estão rodeados por bainhas de esclerênquima. Além disso, ocorrem fibras no interior e no lado externo do feixe vascular, as quais diferem consideravelmente em tamanho, forma e localização, de acordo com a posição em altura e com a espessura da parede do colmo, características estas influenciadas pela espécie de bambu (Liese, 1980, 1985). Existem espécies que apresentam combinação de diferentes tipos de feixes fibro-vasculares, principalmente em função da posição em altura da haste e de sua espessura de parede (Grosser \& Liese, 1971). Nas pesquisas desenvolvidas por Grosser \& Liese (1971) e, posteriormente, por Chaowana et al. (2014), foi demonstrado que existem variações no tamanho e quantidade de feixes vasculares, tanto no sentido longitudinal como transversal.

Com relação à forma, na parte interna do colmo, os feixes vasculares são quase circulares ou arredondados (mais ovais e maiores), alterando gradualmente para forma elíptica (mais longos e menores), ao aproximarem-se da região externa da parede. A variação destas características microscópicas do bambu afeta diretamente as propriedades físicas e mecânicas, interferindo no seu processamento e utilização (Grosser \& Liese, 1971; Liese, 1985; Chaowana et al., 2014).

Além da diferenciação dentro e entre os feixes vasculares, existe variação das dimensões das fibras dos colmos de bambu (Chaowana, 2013; Dixon \& Gibson, 2014; Liese \& Tang, 2015), tanto em comprimento quanto em espessura, em virtude da sua posição na haste, o que pode reduzir ou aumentar a resistência na compressão e tração (Pereira, 2012). As fibras estão presentes nas extremidades dos feixes vasculares como "bainhas de esclerênquima" e são alongadas e afiladas, muitas vezes bifurcadas nas extremidades e alinhadas na direção longitudinal do colmo (Nayak \& Mishra, 2016). Estas fibras servem de proteção para os feixes vasculares, compondo o tecido mecânico da planta, o qual tem por função essencial dar resistência ao indivíduo. Ainda que representem cerca de $40-50 \%$ da área total de seu tecido, constituem entre $60-70 \%$ de sua massa, considerando-se peso total (Liese, 1980; Pereira \& Beraldo, 2007; Nayak \& Mishra, 2016). Por sua vez, no sentido longitudinal ocorre aumento no comprimento da fibra até aproximadamente $60 \%$ da distância entre a região próxima ao nó inferior e o superior, invertendo-se esta tendência, principalmente nos $10 \%$ finais do entrenó (Liese, 1985).
A densidade das fibras, na seção transversal do bambu, varia ao longo da sua espessura, ocorrendo um aumento da porcentagem do interior para o exterior enquanto o teor de parênquima diminui. $\mathrm{O}$ tamanho do feixe vascular é grande na camada interna e média, tendendo para menor e mais denso na camada externa (Chaowana, 2013; Chaowana et al., 2014). No sentido longitudinal, as fibras mais longas estão situadas na parte mediana e as mais curtas nas extremidades, próximas aos nós (Tomazello Filho \& Azzini, 1987; Pereira \& Beraldo, 2007).

A região superior da haste de bambu apresenta maior proporção de fibras, resultando em superior esbeltez do material, em comparação à sua parte basal, que contém mais parênquima (Grosser \& Liese, 1971). Essas variações no teor de fibras interferem na densidade e nas propriedades que devem ser consideradas para seu uso.

Em geral, a distribuição percentual dos elementos constituintes do bambu (parênquima, fibras e células condutoras) mostra um padrão definido. Além disso, a parte externa (córtex) é constituída por células epidérmicas cobertas com uma camada cerosa que impedem a perda de umidade do colmo (Chaowana, 2013; Nayak \& Mishra, 2016). O parênquima e as células condutoras são mais frequentes no terço inferior da haste, enquanto que no terço superior a porcentagem de fibras é maior. Desta forma, a prática comum de não utilizar a porção superior dos bambus cortado na floresta é, portanto, um desperdício no que diz respeito ao teor de celulose (Grosser \& Liese, 1971; Liese, 1980).

\section{Alterações estruturais em função da idade}

O bambu inicia seu processo de envelhecimento entre os primeiros 3-4 anos de idade, continuando paulatinamente até a sua senescência (Liese \& Weiner, 1997; Liese \& Tang, 2015). Esse processo acaba por interferir no aspecto estrutural, influenciando suas propriedades e, consequentemente, na possibilidade de utilização do material. Isto ocorre devido ao espessamento das paredes de fibras e células do parênquima, o que ocorre pela deposição de lamelas adicionais nas camadas com posterior lignificação, resultando em aumento das propriedades de densidade e resistência. Diferentemente das madeiras, o bambu, por não apresentar crescimento secundário, possui processo de enrijecimento através de oito lamelas, divididas em duas classes, largas e estreitas, que variam em proporção à largura do conjunto de lamelas. Numa comparação com a madeira, essas 
oito lamelas correspondem à parede celular secundária. Informações adicionais podem ser obtidas em consulta aos trabalhos desenvolvidos por Parameswaran \& Liese (1976), Liese (1985) e Liese \& Tang (2015).

Desta forma, os colmos considerados adequados para qualquer utilização possuem idade entre 3 e 4 anos. Os mais jovens e imaturos, devido a um reduzido teor de lignina, apresentam-se menos resistentes, sendo os preferidos para o artesanato pela facilidade de trabalhá-los durante sua utilização. Da mesma forma, o reduzido teor de lignina é considerado um aspecto benéfico durante o processo de polpação. Contudo, a utilização de colmos jovens pode ser considerada prejudicial para a vitalidade da cultura, pois isso pode exigir maior quantidade de energia para o crescimento do restante da população, reduzindo a produtividade no ano seguinte. Depois de transcorridos cerca de 8 a 10 anos, o bambu inicia sua fase natural de senescência. Basicamente, nesta fase da vida do bambu ocorre obstrução dos vasos condutores por tilos e outras substâncias, causando ineficiência fisiológica e provocando a morte de indivíduos dentro de uma touceira, maciço ou bosque de bambu (Liese \& Tang, 2015).

Esta condição, contudo, não causa impacto nas suas propriedades tecnológicas. Somente em situações de debilidade, ocorridas após o florescimento, é que são perceptíveis danos estruturais às propriedades tecnológicas do bambu. Neste cenário, a estrutura do tecido líbero-lenhoso torna-se frágil, sendo que, em muitas ocasiões, todo o cólon se curva e quebra. Ainda que este processo não esteja completamente compreendido (Liese, 2008), o que se sabe é que ele não está associado ao processo de biodegradação, podendo ser resultado de alterações bioquímicas que afetam a composição do material lignocelulósico,

Outro aspecto a ser levado em conta é que não são somente os aspectos internos da composição do colmo de bambu que determinam suas características morfológicas e os parâmetros anatômicos, ainda que estes pareçam bastante estáveis. Eles também sofrem influência das condições locais (Latif \& Liese, 2002). Isto tanto é verdade que um maior teor de fibras pode ocorrer em áreas com condições climáticas mais secas e topografia declivosa, possivelmente redundando em um material com maior densidade e com propriedades de resistência aumentadas. Da mesma forma, condições de sítio com elevada fertilização afetam a produção de brotos, o diâmetro da fibra e a espessura da parede, mas, aparentemente, não a composição anatômica (Abasolo et al., 2005).

\section{Considerações finais}

A anatomia de hastes adultas de bambu, apesar de seguir uma estrutura relativamente padronizada com relação aos teores de parênquima, fibras e feixes vasculares, apresenta diferenças entre os diversos gêneros. Estas diferenças possibilitam classificar este material em quatro diferentes grupos. Com relação às mesmas, constata-se que o parênquima e as células condutoras são mais frequentes no terço interno da parede, enquanto que no terço externo a porcentagem de fibras é maior. Ainda, com relação às variações dos principais elementos do bambu, a porção superior da haste apresenta maior proporção de fibras, em comparação à basal, que contém mais parênquima e feixes vasculares de maiores dimensões. Contudo, os aspectos mais relevantes para a classificação do bambu em diferentes grupos são relativos à forma do feixe fibrovascular e o seu teor de fibra.

Apesar das variações constatadas entre espécies de bambu, aliado ao fato desta planta não apresentar crescimento secundário, não sendo classificado como madeira, este material líbero-lenhoso pode ser utilizado de forma complementar a madeira, desde que seja transcorrido um período de tempo suficiente para consolidar o processo de lignificação de seus elementos anatômicos. Além disso, para usos focados na utilização de suas fibras, o maior potencial se concentra principalmente na porção superior e no terço externo da haste.

\section{Agradecimentos}

À Coordenação de Aperfeiçoamento de Pessoal de Nível Superior (Capes) pela concessão de bolsa de doutorado ao primeiro autor.

\section{Referências}

Abasolo, W. P. et al. Fiber characteristics of Gigantochloalevis and Dendrocalamus asper as influenced by organic fertilizers. Journal of Tropical Forest Science, v. 17, n. 2, p. 297-305, 2005.

Banik, R. L. Morphology and growth. In: Liese, W. \& Köhl, M. (Ed.). Tropical forestry, bamboo: the plant and its uses. Switzerland: Springer International Publishing, 2015. p. 43-89. DOI: 10.1007/9783-319-14133-6_3. 
Bamboo Phylogeny Group. An updated tribal and subtribal classification of the bamboos (Poaceae: Bambusoideae). Bamboo Science \& Culture, v. 24, n. 1, p. 1-10, 2012.

Beraldo, A. L. \& Azzini, A. Bambu: características e aplicações. Guaíba: Agropecuária, 2004. 128 p.

Chaowana, P. Bamboo: an alternative raw material for wood and wood-based composites. Journal of Materials Science Reasearch, v. 2, n. 2, p. 90-102, 2013. DOI: 10.5539/jmsr.v.2n2p90.

Chaowana, P. et al. Bamboo: a functionally graded composite material. Forest Products Journal, v. 65, n. 3/4, p. 48-53, 2014.

Clark, L. G. et al. Bamboo taxonomy and habitat. In: Liese, W. \& Köhl, M. (Ed.). Tropical forestry, bamboo: the plant and its uses. Switzerland: Springer International Publishing, 2015. p. 1-30. DOI: 10.1007/978-3-319-14133-6_3.

Dias Júnior, A. F. et al. Caracterização de briquetes produzidos com resíduos agroflorestais. Pesquisa Florestal Brasileira, v. 34, n. 79, p. 225-234, 2014. DOI: 10.4336/2014.pfb.34.79.613.

Dixon, P. G. \& Gibson, L. J. The structure and mechanics of Moso bamboo material. Journal of the Royal Society Interface, v. 11, p. 1-12, 2014. DOI: 10.1098/rsif.2014.0321.

Filgueiras, T. S. \& Viana, P. L. Bambus brasileiros: morfologia, taxonomia, distribuição e conservação. In: Drumond, P. M. \& Wiedman, G. (Ed.). Bambus no Brasil: da biologia à tecnologia. Rio de Janeiro: ICH, 2017. p. 10-27.

Fujii, T. Cell-wall structure of the culm of Azumanezasa (Pleioblastus chino Max.). Mokuzai Gakkaishi, v. 31, p. 865-872, 1985.

Ghavami, K. et al. Bamboo: functionally graded composite material. Asian Journal of Engineering, v. 4, n. 1, p. 1-10, 2003.

Greco, T. M. \& Cromberg, M. Bambu: cultivo e manejo. Florianópolis: Insular, 2011. 184 p.

Greco, T. M. \& Zannin, A. Tribo Olyreae (Poaceae: Bambusoideae) na Ilha de Santa Catarina, Brasil. Rodriguésia, v. 68, n. 2, p. 557-567, 2017. DOI: $10.1590 / 2175-7860201768218$.

Grosser, D. \& Liese, W. On the anatomy of Asian bamboos, with special reference to their vascular bundles. Wood Science and Technology, v. 5, n. 4, p. 290-312, 1971. DOI: 10.1007/BF00365061.

Habibi, M. K. \& Lu, Y. Crack. Propagation in bamboo's hierarchical cellular structure. Scientific Reports, v. 4, n. 5598, p. 1-7, 2014. DOI: $10.1038 /$ srep05598.

Hakeem, K. R. et al. Bamboo biomass: various studies and potential applications for value-added products. In: Hakeem, K. R. et al. (Ed.). Agricultural biomassed based potential materials. Switzerland: Springer International Publishing, 2015. p. 231-244.

Janssen, J. J. A. Designing and building with bamboo. Beijing: INBAR, 2000. 211 p. (Technical report, 20).

Latif, A. M. \& Liese, W. Culm characteristics of two bamboos in relation to age, height and site. In: Kumar, A. et al. (Ed.). Bamboo for sustainable development. San José, Costa Rica: INBAR, 2002. p. 223-233.

Liese, W. Anatomy and properties of bamboo. In: Liese, W. (Ed.). Bamboos: biology, silvics, properties, utilization. Hamburg: GTZ, 1985. p. 196-208.
Liese, W. Anatomy of bamboo. In: Lessard, G. \& Chouinard, A. (Ed.). Bamboo research in Asia: proceedings of a workshop held in Singapore. Ottawa, CA: IDRC, 1980. p. 161-164.

Liese, W. \& Tang, T. K. H. Properties of the bamboo culm. In: Liese, W. \& Kohl, M. (Ed.).Tropical forestry, bamboo: the plant and its uses. Switzerland: Springer International Publishing. 2015. p. 227-256. DOI: 10.1007/978-3-319-14-133-6_8.

Liese, W. The anatomy of bamboo culms. Beijing: INBAR,1998. 208 p. (Technical report, 18).

Liese, W. The blooming of Melocanna baccifera in Northeast India and its consequences. Bamboo Society of Australia, v. 10, n. 1, p. 20-22, 2008.

Liese, W. \& Weiner, G. Modifications of bamboo culm structures due to ageing and wounding. In: Chapman, G. (Ed.).The bamboos. London: Academic, 1997. p. 313-322.

Miranda, E. M. de. et al. Estrutura populacional e o potencial de uso de Guadua cf. superbana região do Alto Acre. In: Drumond, P. M. \& Wiedman, G. (Ed.). Bambus no Brasil: da biologia à tecnologia. Rio de Janeiro: ICH, 2017. p. 161-178.

Nayak, L. \& Mishra, S. P. Prospect of bamboo as a renewable textile fiber, historical overview, labeling, controversies and regulation. Fashion and Textiles, v. 3, n. 2, p. 1-23, 2016. DOI: 10.1186/ s40691-015-0054-5.

Okahisa, Y. et al. Nanostructural changes in bamboo cell walls with aging and their possible effects on mechanical properties. Journal of Materials Science, v. 53, p. 3972-3980, 2018. DOI: 10.1007/ s10853-017-1886-8.

Panda, H. Bamboo plantation and utilization handbook. Delhi: Asia Pacific Business Press, 2011. 568 p.

Parameswaran, N. \& Liese, W. On the fine structure of bamboo fibres. Wood Science Technology, v. 10, p. 231-246, 1976.

Pereira, M. A. dos R. \& Beraldo, A. L. Bambu de corpo e alma. Bauru: Canal6, 2007. Disponível em: <http://www.canal6.com.br/ ed/wp-content/download/Trecho_inicial_Bambu. pdf $>$. Aceso em: 16 Jul. 2017.

Pereira, M. A. dos R. Projeto Bambu: introdução de espécies, manejo, caracterização e aplicações. Bauru: USP, 2012. 210 p.

Smole, M. S. et al. Plant fibers for textile and technical applications. In: Grundas, S. \& Stepniewski, A. (Ed.). Advances in agrophysical research. London: InTech. 2013. p. 369-397. DOI: 10.5772/52372.

Tomazello Filho, M. \& Azzini, A. Estrutura anatômica, dimensões das fibras e densidade básica de colmos de Bambusavulgaris SCHRAD. Instituto de Pesquisas e Estudos Florestais, n. 36, p. 43-50, 1987.

Tomazello Filho, M. \& Azzini, A. Variação e estrutura dos colmos de bambu (Bambusa vulgaris). O Papel, v. 69, p. 155-161, 1988.

Wang, X. et al. Cell wall structure and formation of maturing fibres of moso bamboo (Phyllostachys pubescens) increase buckling resistance. Journal of the Royal Society Interface, v. 9, p. 988-996, 2012. DOI: 10.1098/rsif.2011.0462.

Yeasmin, L. et al. Bamboo: an overview on its genetic diversity and characterization. Biotech, v. 201, n. 5, p. 1-11. 2014. DOI: 10.1007/ s13205-014-0201-5. 